\title{
ANALISA PENENTUAN OBAT DEMAM ANAK DENGAN MENGGUNAKAN METODE ANALITYCAL HIERARKY PROCESS (AHP)
}

\author{
Elisabet Pahat ${ }^{[1]}$; Eka Wulansari Fridayanthie ${ }^{[2]}$;ri Santoso ${ }^{[3]}$ \\ Program Studi Sistem Informasi, STMIK Nusa Mandiri[1][3] \\ Program Studi Sistem Informasi, Universitas Bina Sarana Informatika ${ }^{[2]}$ \\ www.ubsi.ac.id [2], www.nusamandiri.ac.id[1][3] \\ elisabeth.beth0623@gmail.com[1]; eka.ewf@bsi.ac.id[2] ;tri.tos@nusamandiri.ac.id[3]
}

\begin{abstract}
Drugs have many types, some of these drugs are specifically made for treating adults and some others are specifically for treating toddlers. In addition, the drug is also divided into several criteria, namely composition, dosage, side effects, brand and price. From these various criteria, fever medicine is one of them. Each consumer has a different assessment of the keriteria in determining the fever medication they will choose. Researchers distributed questionnaires to Consumers of Abadi Serang Pharmacy. Where the questionnaire there are three alternative drug choices that are often used. This study aims to create a decision support system for the selection of fever medicines for children under five according to the criteria that has been mentioned to find out which fever medicines are most chosen by Apotek Abadi Serang consumers. This study uses the AHP method to support the selection of the fever drug. AHP method is a structured method that consists of goals, criteria and alternatives that form the basis of appropriate considerations in determining the selection of fever drugs for toddlers effectively in determining decisions, research based on the observations of researchers, that in the selection of fever drugs for children toddlers, parents must be more selective in choosing them. Based on the discussion of the results of data processing, it can be determined that the drug Paracetamol gets the highest rank with a weight of 0.470, the second rank is Ibuprofen with a weight of 0.307, and the third rank is Aspirin with a weight of 0.223 .
\end{abstract}

Keywords: Analytical Hierarchy Process, Fever Drug Selection, Toddlers, Decision Support System.

Intisari-Obat memiliki banyak jenis, sebagian obat tersebut khusus di buat untuk mengobati orang dewasa dan sebagian yang lain khusus untuk mengobati anak balita. Selain itu, obat juga terbagi menjadi beberapa kriteria yaitu komposisi, dosis, efek samping, merk dan harga. Dari berbagai kriteria tersebut, obat demam merupakan salah satu di dalamnya. Setiap konsumen memiliki penilaian yang berbeda terhadap keriteria tersebut dalam menentukan obat demam yang akan mereka pilih. Peneliti membagikan kuesioner kepada konsumen Apotek Abadi Serang. Dimana kuesioner tersebut terdapat tiga alternatif pilihan obat yang sering digunakan. Penelitian ini bertujuan untuk menentukan pilihan obat demam untuk anak balita yang sesuai berdasarkan kriteria yang telah disebutkan untuk mengetahui obat demam yang paling banyak dipilih oleh konsumen Apotek Abadi Serang. Penelitian ini menggunakan metode Analytical Hierarchy Process(AHP) untuk mendukung pemilihan obat demam tersebut. Metode AHP merupakan metode terstruktur yang terdiri dari goal, kriteria dan alternatif yang menjadi dasar dalam pertimbangan yang tepat dalam menentukan pemilihan obat demam untuk anak balita secara efektif dalam menentukan keputusan, penelitian yang dilatar belakangi oleh hasil pengamatan peneliti, bahwa dalam pemilihan obat demam untuk anak balita, orang tua harus lebih selektif dalam memilihnya. Berdasarkan pembahasan dari hasil pengolahan data, dapat ditentukan bahwa obat Paracetamol mendapatkan peringkat paling tinggi dengan bobot 0.470, peringkat kedua adalah Ibuprofen dengan bobot 0.307, dan peringkat ketiga adalah Aspirin dengan bobot 0.223 .

Kata Kunci: Analytical Hierarchy Process, Pemilihan Obat Demam, Anak Balita, Sistem Pendukung Keputusan.

\section{PENDAHULUAN}

Pola hidup, perubahan cuaca, kurangnya olahraga, turunnya daya tahan tubuh seseorang berpengaruh dengan kesehatan. Jika seseorang tidak memperhatikan hal tersebut, penyakit dengan mudahnya akan masuk kedalam tubuh. 
Sebagian besar penyakit memiliki gejala awal demam. Demam adalah gejala berupa naiknya suhu tubuh melebihi normal (temperatur normal tubuh berkisar antara 36-38 derajat celcius) sebagai respon normal tubuh terhadap suatu gangguan. Demam dapat menyerang siapa saja, termasuk anak balita. Terjadinya demam terhadap balita disebabkan karena temperatur tubuh yang mengalami peningkatan diatas batas normal yang telah disebabkan oleh thermostat yang terdapat pada tubuh manusia. Thermostat ini terletak pada salah satu bagian otak yang disebut juga dengan hepotalimus. Fungsi hepotalimus ini sebagai pengatur temperatur tubuh dan menjaga temperatur normal yakni dengan mengirimkan sinyal ke dalam tubuh.

Menurut (Birowo, 2017)Harapan masyarakat akan pelayanan yang berkualitas harus diwujudkan dengan berbagai cara dan upaya, antara lain dengan melayani pasien secara maksimal, menyediakan fasilitas perawatan, alat kesehatan dan tentunya berbagai obat yang berkualitas agar pasien dapat terlayani dengan baik.

Salah satu hal yang mengambat proses pemilihan obat ini terkait pengatahuan yang terbatas mengenai obat-obat maupun petugas kesehatan yang kurang aktif menyampaikan informasi terkait obat-obatan tersebut [Meriati, Goenawi, Wiyono, 2013].

Hambatan lain terjadi dikarenakan sebagian masyarakat juga lebih memilih menggunakan obat yang diramu sendiri yang diperoleh dari turun menurun. Hal ini dikarenakan kurangnya pembinaan dari petugas kesehatan setempat [Fatonah \& Hernawilly, 2012].

Maka dari itu, diperlukan metode untuk membantu pemilihan obat demam yang sesuai dengan kondisi penderita/pasien.

\section{BAHAN DAN METODE}

\section{Pengertian Sistem Pendukung Keputusan}

Menurut (Rahayu, 2018) Sistem Pendukung Keputusan merupakan pengembangan lebih lanjut dari sistem informasi manajementer komputerisasi (Computerzed Management Information System), yang dirancang sedemikian rupa sehingga bersifat interaktif dengan pemakainya. Sistem informasi interaktif yang menyediakan informasi, pemodelan dan kemanipulasian data.

\section{Tahapan Pengambilan Keputusan}

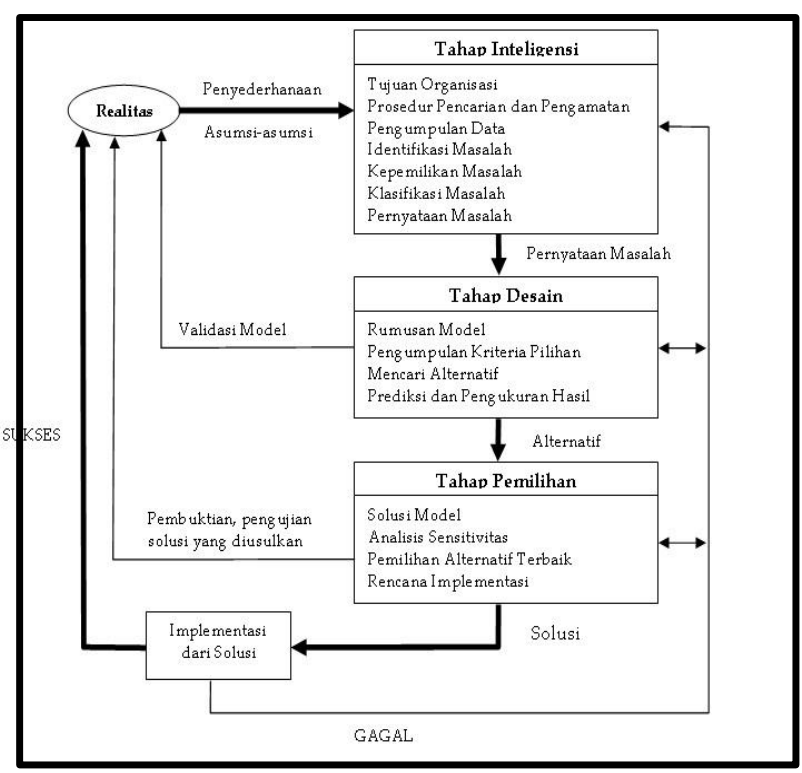

Sumber: Pratiwi (2016:10)

Gambar 1 Tahap Pengambilan Keputusan

Menurut (Pratrama, 2018) Alur atau proses pemilihan alternatif tindakan atau keputusan biasanya terdiri dari langkah-langkah berikut:

1. Tahap Intelligence

Pencarian kondisi-kondisi yang tepat menghasilkan keputusan. Suatu tahap proses seorang dalam rangka pengambil keputusan untuk permasalahan yang dihadapi, terdiri dari aktivitas penelusuran, pendeteksian serta proses pengenalan masalah. Data masukan diperoleh, diuji dalam rangka mengidentifikasi masalah.

2. Tahap Design

Menemukan , mengembangkan, dan menganalisis materi-materi yang mungkin untuk dikerjakan. Tahap proses pengambil keputusan setelah tahap intelligence meliputi proses untuk mengerti masalah, mengenali solusi dan menguji kelayakan solusi. Aktivitas yang biasanya dilakukan seperti menemukan, menggembangkan dan menganalisa alternatif tindakan yang dapat dilakukan.

3. Tahap Choice

Pemilihan dari alternatif pilihan yang tersedia, mana yang akan dikerjakan. Pada tahap ini dilakukan proses pemilihan diantara berbagai alternatif tindakan yang mungkin dijalankan. Hasil pemilihan tersebut kemudian diimplementasikan dalam proses pengambilan keputusan.

4. Tahap Implementation

Implementation dari SPK yang telah dipilih. Tahap Implementasi adalah tahap pelaksanaan dari keputusan yang telah diambil. Pada tahap ini perlu disusun serangkaian tindakan yang terencana, sehingga hasil 
keputusan dapat dipantau dan disesuaikan apabila diperlukan perbaikan.

\section{Pengertian Analytical Hierarchy Process}

Menurut (Kardian, 2015)Analytical Hierarchy Process (AHP) merupakan teknik pengambilan keputusan atau optimasi multivariate yang digunakan dalam analisis kebijaksanaan. Pada hakekatnya AHP merupakan suatu model pengambil keputusan yang komprehensif dengan menghitungkan halhal yang bersifat kualitatif dan kuantitatif.

AHP umumnya digunakan dengan tujuan untuk menyusun prioritas dari berbagai alternatif pilihan yang ada dan pilihan-pilihan tersebut bersifat kompleks atau multikriteria.

\section{Metodologi}

Metode penelitian yang digunakan dalam pengolahan penelitian ini, penulis menetapkan proses pemecahan masalah dalam AHP dengan langkah-langkah penyelesaian berdasarkan empat tahap yaitu mendefinisikan masalah, menentukan prioritas elemen, sintesis dan mengukur konsistensi.

\section{Mendefinisikan Masalah}

Dalam pengelolahan hasil penelitian, dibuatkan beberapa kriteria yang dianggap paling mempengaruhi dalam pengambilan keputusan untuk menentukan pemilihan obat demam anak seperti komposisi, dosis, efek samping, merk dan harga. Dan alternative yang digunakan yaitu 3 (tiga) jenis obat demam yang terdiri dari ibuprofen, aspirin, dan paracetamol

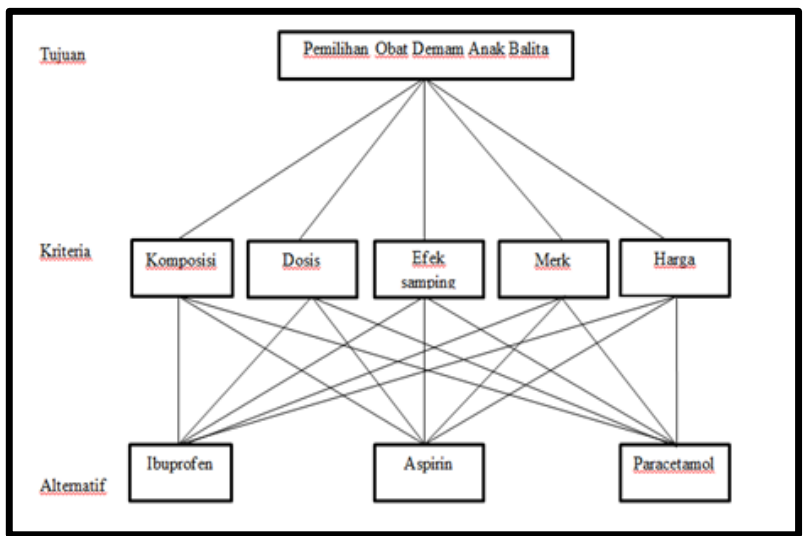

Sumber: Hasil Penelitian (2019)

Gambar 2. Hirarki Pemilihan Obat Demam Anak

\section{Menentukan Prioritas Elemen}

Pada tahap ini penulis membuat perbandingan berpasangan yaitu membandingkan elemen secara berpasangan sesuai kriteria yang diberikan. Dalam mengisi perbandingan berpasangan diisi menggunakan bilangan untuk mempresentasikan kepentingan relative dari suatu elemen terhadap elemen yang lainnya.responden

\section{Data Kriteria Dan Alternatif Pemilihan Obat Demam Anak}

Dalam penelitian ini penulis menggunakan beberapa kriteria dan alternatif dalam pengolahan data dengan menggunakan MS.Excel, dimana kriteria yang terdiri dari komposisi, dosis, efek samping, merk, dan harga, maka selanjutnya adalah menginput data perbandingan alternatif. Alternatif yang dipilih harus memenuhi kriteria yang sebelumnya sudah diperoleh yakni Ibuprofen, Aspirin, Parasetamol

\section{Sintesis}

Dalam melakukan pertimbangan terhadap kriteria, matriks perbandingan akan dilakukan dengan cara sintesis. Tujuan dilakukannya sintesis yaitu agar memperoleh keseluruhan prioritas.

Hal - hal yang dilakukan dalam langkah ini yaitu:

1. Menjumlahkan nilai-nilai dari setia kolom pada matriks

2. Membagi setiap nilai dari kolom dengan total kolom yang bersangkutan untuk memperoleh normalisasi matriks.

3. Menjumahkan nilai-nilai dari setiap baris dan membaginya dengan jumlah elemen untuk mendapatkan nilai ratarata.

Untuk sintesis dilakukan sebanyak jumlah matriks perbandingan yang sudah dibuat.

Dalam penelitian ini sintesis yang ada meliputi:

1. Sintesis level 1 berdasarkan kriteria utama

2. Sintesis level 2 berdasarkan Komposisi

3. Sintesis level 2 berdasarkan Dosis

4. Sintesis level 2 berdasarkan Efek Samping

5. Sintesis level 2 berdasarkan Merk

6. Sintesis level 2 berdasarkan Harga

\section{HASIL DAN PEMBAHASAN}

Berikut merupakan pengolahan hasil dari penelitian ini.

\section{A. Sintesis Level 1 Berdasarkan Kriteria Utama}


Setelah melakukan pengolahan data responden berdasarkan kriteria utama, maka diperoleh hasil penjumlahan.

Tabel 1. Penjumlahan Nilai Kolom Kriteria Utama

\begin{tabular}{cccccc}
\hline Kriteria & Komposisi & Dosis & $\begin{array}{c}\text { Efek } \\
\text { Samping }\end{array}$ & Harga & Merk \\
\hline Komposisi & 1.000 & 0.927 & 0.425 & 0.749 & 1.240 \\
\hline Dosis & 1.079 & 1.000 & 1.316 & 0.823 & 1.547 \\
\hline $\begin{array}{c}\text { Efek } \\
\text { Samping }\end{array}$ & 2.354 & 0.760 & 1.000 & 0.417 & 0.630 \\
\hline Harga & 1.335 & 2.397 & 1.215 & 1.000 & 0.738 \\
\hline Merk & 0.807 & 1.588 & 1.354 & 0.646 & 1.000 \\
\hline Total & 6.575 & 6.673 & 5.310 & 3.635 & 5.155 \\
\hline Sumber
\end{tabular}

Sumber : Data Diolah, 2019

Tabel 2. Normalisasi Kriteria Utama

\begin{tabular}{ccccccc}
\hline Kriteria & $\begin{array}{c}\text { Kompo } \\
\text { sisi }\end{array}$ & Dosis & $\begin{array}{c}\text { Efek } \\
\text { Samping }\end{array}$ & Harga & Merk & $\begin{array}{c}\text { Rata- } \\
\text { Rata }\end{array}$ \\
\hline Komposisi & 0.152 & 0.139 & 0.080 & 0.206 & 0.240 & 0.164 \\
\hline Dosis & 0.164 & 0.150 & 0.248 & 0.226 & 0.300 & 0.218 \\
\hline $\begin{array}{c}\text { Efek } \\
\text { Samping }\end{array}$ & 0.358 & 0.114 & 0.188 & 0.115 & 0.122 & 0.179 \\
\hline Harga & 0.203 & 0.359 & 0.229 & 0.275 & 0.143 & 0.242 \\
\hline Merk & 0.123 & 0.238 & 0.255 & 0.178 & 0.194 & 0.197 \\
\hline
\end{tabular}

Sumber : Data Diolah, 2019

Berdasarkan Tabel 2 setelah nilai total perhitungan setiap kriteria dihitung dengan Vector Eigen, diketahui bahwa kriteria Harga memiliki nilai total prioritas tertinggi yaitu sebesar 0.242, Dosis sebesar 0.218, Merk sebesar 0.197, Efek Samping sebesar 0.179 dan yang terakhir Komposisi sebesar 0.167.

Konsistensi Indeks memperoleh nilai 0.092 atau kurang dari 10\%, lamda 5.369 dan Rasio Konsistensi 0.082. Nilai inkonsistensi sebesar 0.092 sehingga hasil penilaian masih dapat diterima. Hal ini di karenakan batas toleransi inkonsistensi $\leq 10 \%$ atau 0.1 .

Jadi berdasarkan perhitungan Vector Eigen, didapatkan kriteria yang paling diperhatikan dalam proses pemilihan Obat Demam Anak Balita adalah:
1. Harga
2. Dosis
3. Merk
4. Efek Samping
5. Komposisi

\section{B. Sintesis Level 2 Berdasarkan Komposisi}

Diketahui hasil pengolahan data pada pemilihan obat demam anak berdasarkan perbandingan alternatif komposisi, maka proses perhitungannya sebagai berikut:

Tabel 3. Penjumlahan Nilai Kolom Komposisi

\begin{tabular}{cccc}
\hline Alternatif & Ibuprofen & Aspirin & Paracetamol \\
\hline Ibuprofen & 1.000 & 0.900 & 1.082 \\
\hline Aspirin & 1.111 & 1.000 & 0.309 \\
\hline Paracetamol & 0.924 & 3.239 & 1.000 \\
\hline Total & 3.035 & 5.139 & 2.391
\end{tabular}

Sumber : Data Diolah, 2019

Tabel 4. Normalisasi Komposisi

\begin{tabular}{cccc}
\hline Alternatif & Ibuprofen & Aspirin & Paracetamol \\
\hline Ibuprofen & 0.330 & 0.175 & 0.453 \\
\hline Aspirin & 0.366 & 0.195 & 0.129 \\
\hline Paracetamol & 0.304 & 0.630 & 0.418 \\
\hline \multicolumn{3}{r}{ Vektor Eigen } \\
\hline
\end{tabular}

Sumber : Data Diolah 2019

Tabel 5. Nilai Rata-Rata Komposisi

\begin{tabular}{ccccc}
\hline Alternatif & Ibuprofen & Aspirin & $\begin{array}{c}\text { Parace } \\
\text { tamol }\end{array}$ & $\begin{array}{c}\text { Rata- } \\
\text { Rata }\end{array}$ \\
\hline Ibuprofen & 0.330 & 0.175 & 0.453 & 0.319 \\
\hline Aspirin & 0.366 & 0.195 & 0.129 & 0.230 \\
\hline Paracetamol & 0.304 & 0.630 & 0.418 & 0.451 \\
\hline
\end{tabular}

Sumber : Data Diolah 2019

Dilihat dari Tabel 5 nilai total perhitungan dari masing-masing alternatif dihitung dengan Vector Eigen, diketahui bahwa alternatif Paracetamol mempunyai nilai total prioritas tertinggi yaitu sebesar 0.451, alternatif Ibuprofen dengan total 0.319, dan urutan terakhir alternatif Aspirin dengan total 0.230.

Konsistensi Indeks didapatkan nilai 0.056 atau 10\%, lamda 3.111 dan Rasio Konsistensi 0.096. Nilai inkosistensi sebesar 0.056 sehingga hasil penilaian masih dapat diterima. Hal ini di karenakan batas toleransi inkonsistensi $\leq 10 \%$ atau 0.1 .

Jadi dari perhitungan Vector Eigen , didapatkan alternatif yang paling diperhatikan dalam proses pemilihan Obat Demam Anak adalah:
1. Paracetamol
2. Ibuprofen
3. Aspirin

\section{Sintesis Level 2 Berdasarkan Dosis}

Hasil pengolahan data pada pemilihan obat demam anak berdasarkan perbandingan 
alternatif dosis, maka proses perhitungannya sebagai berikut:

Tabel 6. Penjumlahan Nilai Kolom Dosis

\begin{tabular}{cccc}
\hline Alternatif & Ibuprofen & Aspirin & Paracetamol \\
\hline Ibuprofen & 1.000 & 1.875 & 0.569 \\
\hline Aspirin & 0.533 & 1.000 & 0.702 \\
\hline Paracetamol & 1.759 & 1.424 & 1.000 \\
\hline Total & 3.292 & 4.299 & 2.271 \\
\hline
\end{tabular}

Sumber : Data Diolah, 2019

Tabel 7. Normalisasi Dosis

\begin{tabular}{cccc}
\hline Alternatif & Ibuprofen & Aspirin & Paracetamol \\
\hline Ibuprofen & 0.304 & 0.436 & 0.250 \\
\hline Aspirin & 0.162 & 0.233 & 0.309 \\
\hline Paracetamol & 0.534 & 0.331 & 0.440 \\
\hline \multicolumn{2}{c}{ Vector Eigen } & & 1.000
\end{tabular}

Sumber : Data Diolah , 2019

Tabel 8. Nilai Rata-Rata Dosis

\begin{tabular}{ccccc}
\hline Alternatif & Ibuprofen & Aspirin & Paracetamol & $\begin{array}{c}\text { Rata- } \\
\text { Rata }\end{array}$ \\
\hline Ibuprofen & 0.304 & 0.436 & 0.250 & 0.330 \\
\hline Aspirin & 0.162 & 0.233 & 0.309 & 0.235 \\
\hline Paracetamol & 0.534 & 0.331 & 0.440 & 0.435 \\
\hline
\end{tabular}

Sumber : Data Diolah, 2019

Berdasarkan Tabel 8 nilai total perhitingan dari masing-masing alternatif dihitung dengan vector Eigen, diketahui bahwa alternatif Paracetamol memperoleh nilai total prioritas tertinggi yaitu sebesar 0.435 , alternatif Ibuprofen sebesar 0.330 dan urutan yang terakhir alternatif Aspirin sebesar 0.235.

Konsistensi Indeks memperoleh nilai 0.040 atau kurang dari 10\%, lamda 3.079 dan Rasio Konsistensi 0.068. Nilai inkonsistensi sebesar 0.040 sehingga hasil penilaian masih dapat diterima. Hal ini di karenakan batas toleransi inkonsistensi $\leq 10 \%$ atau 0.1 .

Jadi, berdasarkan perhitungan vector Eigen, didapatkan alternatif yang paling diperhatikan dalam proses pemilihan Obat Demam untuk Anak Balita adalah:

1. Paracetamol

2. Ibuprofen

3. Aspirin

\section{Sintesis Level 2 Berdasarkan Efek Samping}

Dari hasil pengolahan data pada pemilihan obat demam untuk anak balita berdasarkan perbandingan alternatif efek samping, maka proses perhitungannya sebagai berikut:

Tabel 9. Penjumlahan Nilai Kolom Efek Samping

\begin{tabular}{cccc} 
Alternatif & Ibuprofen & Aspirin & Paracetamol \\
\hline Ibuprofen & 1.000 & 1.240 & 0.796 \\
\hline Aspirin & 0.807 & 1.000 & 0.343 \\
\hline Paracetamol & 1.257 & 2.912 & 1.000 \\
\hline Total & 3.064 & 5.152 & 2.139 \\
\hline
\end{tabular}

Sumber : Data Diolah, 2019

Tabel 10. Normalisasi Efek Samping

\begin{tabular}{|c|c|c|c|}
\hline Alternatif & Ibuprofen & Aspirin & Paracetamol \\
\hline Ibuprofen & 0.326 & 0.241 & 0.372 \\
\hline Aspirin & 0.263 & 0.194 & 0.161 \\
\hline Paracetamol & 0.410 & 0.565 & 0.468 \\
\hline
\end{tabular}

Sumber : Data Diolah, 2019

Tabel 11. Nilai Rata-Rata Efek Samping

\begin{tabular}{ccccc}
\hline Alternatif & Ibuprofen & Aspirin & Paracetamol & $\begin{array}{c}\text { Rata- } \\
\text { Rata }\end{array}$ \\
\hline Ibuprofen & 0.326 & 0.241 & 0.372 & 0.313 \\
\hline Aspirin & 0.263 & 0.194 & 0.161 & 0.206 \\
\hline Paracetamol & 0.410 & 0.565 & 0.468 & 0.481 \\
\hline
\end{tabular}

Sumber : Data Diolah, 2019

Berdasarkan Tabel 11 nilai total perhitungan dari masing-masing alternatif dihitung dengan vector Eigen, diketahui bahwa alternatif Paracetamol memperoleh nilai total prioritas tertinggi yaitu sebesar 0.481 , alternatif Ibuprofen sebesar 0.313 dan urutan yang terakhir alternatif Aspirin sebesar 0.206.

Konsistensi Indeks memperoleh nilai 0.022 atau kurang dari 10\%, lamda 3.044 dan Rasio Konsistensi 0.038 . Nilai inkonsistensi sebesar 0.022 sehingga hasil penilaian masih dapat diterima. Hal ini di karenakan batas toleransi inkonsistensi $\leq 10 \%$ atau 0.1 .

Jadi, berdasarkan perhitungan vector Eigen, didapatkan alternatif yang paling diperhatikan dalam proses pemilihan Obat Demam Anak adalah:

1. Paracetamol

2. Ibuprofen

3. Aspirin

\section{E. Sintesis Level 2 Berdasarkan Merk}

Dari hasil pengolahan data pada pemilihan obat demam anak berdasarkan perbandingan alternatif Merk maka proses perhitungannya sebagai berikut: 
Tabel 12. Penjumlahan Nilai Kolom Merk

\begin{tabular}{cccc}
\hline Alternatif & Ibuprofen & Aspirin & Paracetamol \\
\hline Ibuprofen & 1.000 & 0.831 & 0.758 \\
\hline Aspirin & 1.204 & 1.000 & 0.337 \\
\hline Paracetamol & 1.320 & 2.967 & 1.000 \\
\hline Total & 3.523 & 4.798 & 2.095
\end{tabular}

Sumber : Data Diolah, 2019

Tabel 13. Normalisasi Merk

\begin{tabular}{cccc}
\hline Alternatif & Ibuprofen & Aspirin & Paracetamol \\
\hline Ibuprofen & 0.284 & 0.173 & 0.362 \\
\hline Aspirin & 0.342 & 0.208 & 0.161 \\
\hline Paracetamol & 0.374 & 0.618 & 0.477 \\
\hline \multicolumn{2}{c}{ Vector }
\end{tabular}

Vector Eigen

1.000

Sumber : Data Diolah,2019

Tabel 14. Nilai Rata-Rata Merk

\begin{tabular}{ccccc}
\hline Alternatif & Ibuprofen & Aspirin & Paracetamol & $\begin{array}{c}\text { Rata- } \\
\text { Rata }\end{array}$ \\
\hline Ibuprofen & 0.284 & 0.173 & 0.362 & 0.273 \\
\hline Aspirin & 0.342 & 0.208 & 0.161 & 0.237 \\
\hline Paracetamol & 0.374 & 0.618 & 0.477 & 0.490 \\
\hline
\end{tabular}

Sumber : Data Diolah ,2019

Berdasarkan Tabel 14 nilai total perhitungan dari masing-masing alternatif dihitung dengan vector Eigen, diketahui bahwa alternatif Paracetamol memperoleh nilai total prioritas tertinggi yaitu sebesar 0.490, alternatif Ibuprofen sebesar 0.273 dan urutan yang terakhir alternatif Aspirin sebesar 0.237.

Konsistensi Indeks memperoleh nilai 0.056 atau $10 \%$, lamda 3.112 dan Rasio Konsistensi 0.096 . Nilai inkonsistensi sebesar 0.056 sehingga hasil penilaian masih dapat diterima. Hal ini di karenakan batas toleransi inkonsistensi $\leq 10 \%$ atau 0.1 .

Jadi, berdasarkan perhitungan vector Eigen, didapatkan alternatif yang paling diperhatikan dalam proses pemilihan Obat Demam Anak adalah:

1. Paracetamol

2. Ibuprofen

3. Aspirin

\section{F. Sintesis Level 2 Berdasarkan Harga}

Dari hasil pengolahan data pada pemilihan obat demam anak berdasarkan perbandingan alternatif harga maka proses perhitungannya sebagai berikut:

Tabel 15. Penjumlahan Nilai Kolom Harga

\begin{tabular}{cccc}
\hline Alternatif & Ibuprofen & Aspirin & Paracetamol \\
\hline Ibuprofen & 1.000 & 1.240 & 0.753 \\
\hline Aspirin & 0.807 & 1.000 & 0.343 \\
\hline Paracetamol & 1.329 & 2.912 & 1.000 \\
\hline Total & 3.135 & 5.152 & 2.096
\end{tabular}

Sumber : Data Diolah, 2019

Tabel 16. Normalisasi Harga

\begin{tabular}{cccc}
\hline Alternatif & Ibuprofen & Aspirin & Paracetamol \\
\hline Ibuprofen & 0.319 & 0.241 & 0.359 \\
\hline Aspirin & 0.257 & 0.194 & 0.164 \\
\hline Paracetamol & 0.424 & 0.565 & 0.477 \\
\hline \multicolumn{3}{c}{ Vector Eigen } & 1.000 \\
\hline
\end{tabular}

Sumber : Data Diolah, 2019

Tabel 17. Nilai Rata-Rata Harga

\begin{tabular}{ccccc} 
Alternatif & Ibuprofen & Aspirin & $\begin{array}{r}\text { Parace } \\
\text { tamol }\end{array}$ & $\begin{array}{c}\text { Rata- } \\
\text { Rata }\end{array}$ \\
\hline Ibuprofen & 0.319 & 0.241 & 0.359 & 0.306 \\
\hline Aspirin & 0.257 & 0.194 & 0.164 & 0.205 \\
\hline Paracetamol & 0.424 & 0.565 & 0.477 & 0.489
\end{tabular}

Sumber : Data Diolah, 2019

Berdasarkan Tabel 17 nilai total perhitungan dari masing-masing alternatif dihitung dengan vector Eigen, diketahui bahwa alternatif Paracetamol memperoleh nilai total prioritas tertinggi yaitu sebesar 0.489, alternatif Ibuprofen sebesar 0.306 dan urutan yang terakhir alternatif Aspirin sebesar 0.205.

Konsistensi Indeks memperoleh nilai 0.018 atau kurang dari 10\%, lamda 3.036 dan Rasio Konsistensi 0.031 . Nilai inkonsistensi sebesar 0.018 sehingga hasil penilaian masih dapat diterima. Hal ini di karenakan batas toleransi inkonsistensi $\leq 10 \%$ atau 0.1 .

Jadi, berdasarkan perhitungan vector Eigen, didapatkan alternatif yang paling diperhatikan dalam proses pemilihan Obat Demam Anak adalah:

1. Paracetamol

2. Ibuprofen

3. Aspirin

Dari vector eigen keputusan terlihat bahwa:

1. Paracetamol memeliki bobot prioritas tertinggi yaitu 0.470

2. Ibuprofen memiliki bobot prioritas urutan kedua yaitu 0.307

3. Aspirin memiliki bobot prioritas terendah yaitu 0.223 
Jika digambarkan dalam bentuk grafik, maka dapat dilihat jumlah presentasenya sebagai berikut:

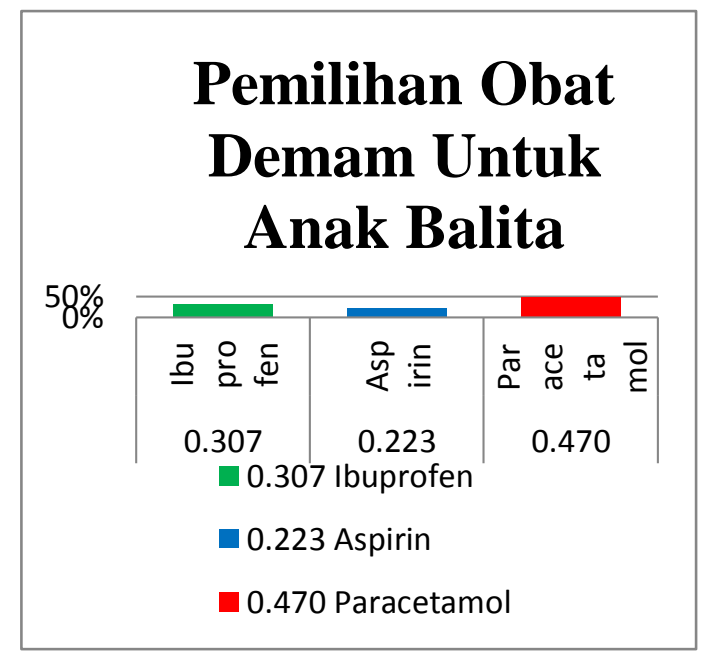

Gambar 3. Persentase Vektor Eigen Keputusan

Berdasarkan vector eigen keputusan, maka pihak konsumen apotek Abadi Serang akan melakukan proses penentuan pemilihan obat demam untuk anak balita.

Setelah melakukan tahap perhitungan data di tingkat kriteria dan alternatif, maka tahap selanjutnya dilakukan perhitungan terhadap data akhir , apakah konsisten atau tidak.

Perhitungan Rasio Consistensi Hierarci (CRH) dilakukan dengan cara membagi Concictency Index Hieraci $(\mathrm{CIH})$ dengan Rasio Index Hierarci (RIH) dapat dilakukan dengan rumus :

$\mathrm{CRH}=\mathrm{CIH} / \mathrm{RIH}$

Dimana:

$\mathrm{CIH} \rightarrow$ CI Level $1+$ (Vektor eigen level 1) (CI level 2)

$\begin{array}{cccc}0.092+c(0.164 & 0.218 & 0.179 & 0.242 \\ 0.197) & 0.056 & & \end{array}$

$$
\left(\begin{array}{l}
0.040 \\
0.022 \\
0.056 \\
0.018
\end{array}\right)
$$

$0.092+0.030=0.123$

$\mathrm{RIH} \rightarrow$ RI Level $1+$ (Vektor eigen level 1) (RI level 2)

$$
1.120+\left(\begin{array}{lllll}
0.164 & 0.218 & 0.179 & 0.242 & 0.197
\end{array}\right)
$$

$$
1.120
$$

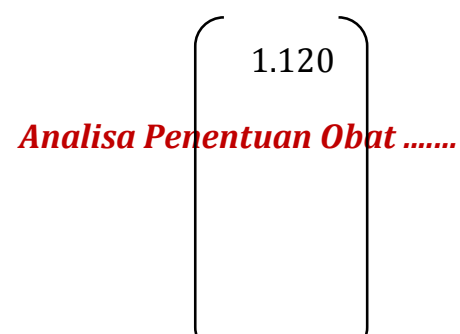

$1.120+1.120=2.240$

$\mathrm{CRH} \rightarrow 0.123 / 2.240=0.055$

Dari perhitungan yang diatas diperoleh nilai dari CRH dari 0,1 atau kurang dari 10\%, maka hirarki secara keseluruhan bersifat konsistensi, sehingga kesimpulan yang diperoleh dapat diterima, artinya keputusan yang ditetapkan dapat diandalkan.

Oleh karena itu, kesimpulannya didapatkan dari hasil yang telah diperoleh sudah sesuai terhadap hasil hipotesis yang menyatakan bahwa terdapat pengaruh spk pemilihan obat demam untuk anak terhadap pembelian para konsumen.

\section{KESIMPULAN}

Metode Analytical Hierarchy Process dapat digunakan untuk sistem pendukung keputusan pemilihan obat demam untuk anak balita, dengan menentukan kriteria dan alternatif yang akan digunakan dengan membentuk sebuah hierarki sehingga dapat membantu dalam melihat permasalahan yang dihadapi secara lebih terperinci.

Didalam penelitian ini terdapat lima kriteria utama yang digunakan yaitu Komposisi, Dosis, Efek Samping, Merk dan Harga. Dimana dari lima kriteria ini sudah mendapatkan hasil pengolahan data dari kuesioner, ditemukan bahwa harga menjadi kriteria yang tertinggi dalam pemilihan obat demam untuk anak dengan bobot 0.242 .

Pada penelitian ini digunakan tiga alternatif yaitu Ibuprofen, Aspirin dan Paracetamol. Dari tiga alternatif ini Paracetamol menjadi alternatif yang lebih prioritas dengan bobot $47 \%$.

Dari hasil perhitungan kuesioner yang telah dibagikan kepada responden menggunakan nilai konsistensi dibawah 0,1 menunjukkan bahwa nilai konsisistensi penilaian cukup baik.

Urutan prioritas dari ketiga obat demam bagi anak balita yang dijadikan objek dalam penelitian ini adalah Paracetamol yang menduduki prioritas pertama dengan bobot yaitu 0.470 , yang kedua Ibuprofen dengan bobot 0.307, dan urutan terakhir Aspirin dengan bobot yaitu 0.223 .

Dengan demikian, obat demam anak yang banyak dipilih oleh konsumen dengan 
menggunakan Analytical Hierarchy Process (AHP) bagi konsumen Apotek Abadi serang adalah Paracetamol.

Penelitian yang dilakukan adalah dengan menggunakan metode AHP, untuk penelitian selanjutnya bisa dikembangkan dengan metode yang lain misalnya dengan SAW atau ANP.

Dalam melakukan perhitungan berpasangan baik tujuan, kriteria dan alternatif , harus dilakukan dengan hati-hati, agar tidak terjadi kesalahan. Jika terjadi kesalahan pada pemasukan data dapat menyebabkan hasil akhir yang diperoleh tidak tidak terpenuhi atau nilai inkonsistensinya salah.

\section{REEFERENS}

Birowo, S. (2017). Analisa Faktor Pendukung Pemilihan Obat Untuk Penderita Penyakit Hipertensi Dengan Metode AHP (Analytical Hierarchy Process). Jurnal Informatika, 1-8.

Fatonah, Siti. Hernawilly. (2012). Perilaku Pemilihan Obat Tradisional Untuk Menurunkan Tekanan Darah Pada Lansia Di Kota Bandar Lampung. Jurnal Keperawatan. Volume VIII. No. 1. ISSN 1907 - 0357.

Kardian, R. (2015). Sistem Penunjang Keputusan Pada Wedding Organizer "The Puple House" Dengan Metode Analytical Hierarchy Process (AHP) Menggunakan Framework Codeigniter. 1-13.

Meriati, Ni Wayan Eka. Goenawi, Lily Ranty. Wiyono, Wenny. (2013). Dampak Penyuluhan Pada Pengetahuan Masyarakat Terhadap Pemilihan Dan Penggunaan Obat Batuk Swamedikasi Di Kecamatan Malalayang. Jurnal Ilmiah Farmasi - UNSRAT. Vol. 2 No. 03. ISSN 2302-2493.

Pratiwi. (2016). Buku Ajar Sistem Pendukung Keputusan. Yogyakarta: Depublish.

Pratrama. (2018). Sistem Pendukung Keputusan Supplier Menggunakan Metode AHP Pada PT. Transcoal Pacific Jakarta. 2135.

Rahayu, M. S. (2018). Menentukan Kelayakan Tunjangan Kesejahteraan Pegawai Menggunakan Metode AHP. 46-55.

Riadi. (2015). Metode Statistik Parametrik NonParametrik. Tangerang: Pustaka Mandiri. 